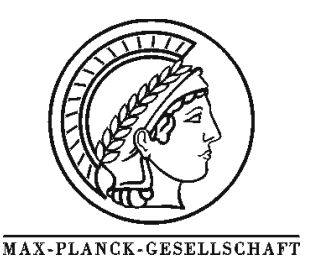

\title{
Fullerene-like Soot from EURO-IV Diesel Engine: Consequences for Catalytic Automotive Pollution Control
}

\author{
D.S. Su ${ }^{\text {a, }}{ }^{*}$, J.-O. Müller ${ }^{a}$, R.E. Jentoft ${ }^{a}$, D. Rothe ${ }^{\text {b }}$ E. Jacob ${ }^{b}$, R.Schlögl ${ }^{a}$ \\ ${ }^{\text {a }}$ Department of Inorganic Chemistry, Fritz-Haber-Institute of the MPG, Faradayweg 4-6, 14195 Berlin, Germany \\ ${ }^{\mathrm{b}}$ MAN Nutzfahrzeuge Gruppe, Geschäftseinheit Motoren, Abt. MTVN, Vogelweiherstr. 33, 90441 Nürnberg
}

* Corresponding author: e-mail dangsheng@,fhi-berlin.mpg.de, phone +49 308413 5406, fax +49 3084134405

\begin{abstract}
Soot particulates from an EuroIV diesel engine are sampled and investigated by high-resolution electron microscopy (HRTEM) and thermal gravimetry (TG). The experiments reveal a drastic reduction of primary particle size down to less than $20 \mathrm{~nm}$, much smaller than that emitted by earlier diesel engines. HRTEM reveals primary particles with deformed fullerenoid structures. The defective fullerenoid soot is more prone to oxidation than the soot of a black smoking diesel engine. Our findings may initiate a critical review of the current strategy for the reduction of soot emission from diesel engines. The newly developed engines reduce the quantity of soot emitted, they also emit smaller soot particles with a fullerene-like structure into the exhaust.
\end{abstract}

Keywords: Diesel engine, soot, fullerenic carbon, HRTEM, TG

\section{Introduction}

Soot particulate in the exhaust from diesel engines is subject to increasing criticism as being a potential risk to public health. Worldwide legislation has tightened the particulate standards for diesel engines over the last decade. These restrictions have induced a rapid improvement of heavy-duty diesel engines and exhaust emission control systems. The particulate matter (PM) emission standard will be reduced to $20 \mathrm{mg} / \mathrm{kWh}$ (ESC) in 2005 (EuroIV engine) as compared with $100 \mathrm{mg} / \mathrm{kWh}$ for the current EuroIII engine [1]. A prerequisite for further technical improvement of particulate emission control systems is precise information about the micro-morphology, microstructure, and oxidative behaviour of soot originating from the new diesel engines that run under optimised combustion conditions. In the present work we use TEM and TG to investigate the microstructure/micro-morphology and oxidation behaviour of the soot particles collected from the raw exhaust of an optimised low-emission EuroIV diesel engine run at stationary (ESC) conditions (labelled as F-soot). The results are compared with the characteristics of soot from a black smoking diesel engine (labelled as G-soot).

\section{Experimental}

The F-soot was produced in an EuroIV test diesel engine of the MAN group (6.91 displacement, $228 \mathrm{~kW}$ ); equipped with double step controlled charging and external controlled cooled exhaust gas recirculation. The maximal exhaust gas flow at rated speed and full load was $1.200 \mathrm{Nm}^{3} / \mathrm{h}$. In order to avoid potential structural change during the soot sampling, samples were collected directly from the exhaust gas of the engine using a special particle collector that was heated to the exhaust gas temperature. Copper grids with a diameter of $3 \mathrm{~mm}$ and coated with a holey carbon film were fixed in a closed compartment. The collector was attached to the exhaust pipe of the engine, and the exhaust gas was directed through the copper grids. The grids served as a filter to collect the soot particulates. The G-soot sample originates 
from a D2876 CR-Engine at 30\% load (artificially adjusted for high soot emission by air throttling and reducing rail pressure, blackening number 5).

A Philips TEM/STEM CM 200 FEG transmission electron microscope equipped with a field-emission gun was used to study the morphology and microstructure of the soot. The acceleration voltage was set to $200 \mathrm{kV}$. To avoid any faults in interpreting the image contrast, images of the soot particles were taken without underlying carbon film. The TG/DSC data was measured using a Netzsch-STA 449 instrument with $\mathrm{Al}_{2} \mathrm{O}_{3}$ crucibles. The samples were evacuated and the sample chamber was re-filled with $5 \% \mathrm{O}_{2}$ in $\mathrm{N}_{2}$ or $\mathrm{He}$ which was maintained at a total flow rate of $100 \mathrm{ml} / \mathrm{min}$. A heating rate of $5 \mathrm{~K} / \mathrm{min}$ was used. The gas phase products were transferred through a heated quartz capillary to a Balzers, OmniStar quadrupol mass spectrometer operated in SIM mode. The only products observed were $\mathrm{CO}_{2}(\mathrm{~m} / \mathrm{e} 44-$ 46) and $\mathrm{H}_{2} \mathrm{O}(\mathrm{m} / \mathrm{e} \mathrm{17-18)}$. The sample charge used for TG analysis was about $2 \mathrm{mg}$ for G-soot and $1 \mathrm{mg}$ for F-soot.

\section{Results}

\subsection{Size-distribution}

Fig. 1a shows an electron micrograph of the F-soot particulates emitted by an EuroIV engine (ESC speed B, 25\% load). The particulates are agglomerates of primary particles forming a secondary chain-like structure with final dimensions of up to 500 nanometers. The size distribution of primary particles evaluated from TEM is plotted in Fig. 2. The projected diameter of the primary particles is about $13 \mathrm{~nm}$. The electron micrograph in Fig.1b show the G-soot particulate sampled from the black smoking EuroIII diesel engine. The G-soot contains large spherical particles agglomerated to a chain-like secondary structure. The evaluated sizedistribution of primary particles is also given in Fig. 2, with a maximum at $35 \mathrm{~nm}$. From Fig. 2 we also see that the size distribution of F-soot primary particles is much narrower than that of the G-soot primary particles. Our findings reveal that the improved EuroIV diesel engine reduces not only the amount of emitted soot [2], but also reduces the size of primary particles emitted in the exhaust. It is worth noting that previous measures applied to reduce soot emission from diesel engines had little influence on the size-distribution of the emitted particulate, and only reduced the quantity of the emitted particulate [3]
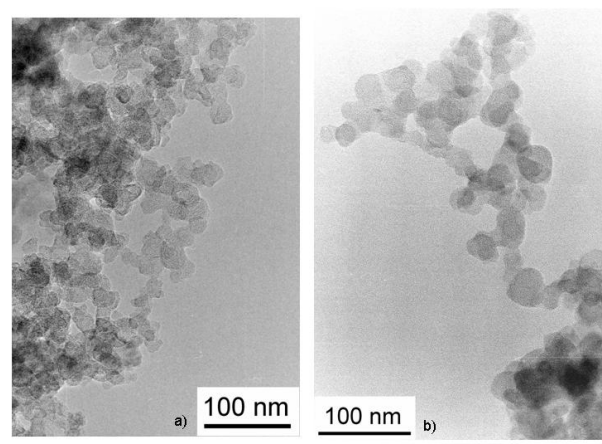

Figure 1: Sampled soot particles: a) EuroIV engine, b) engine operating at black smoke conditions.

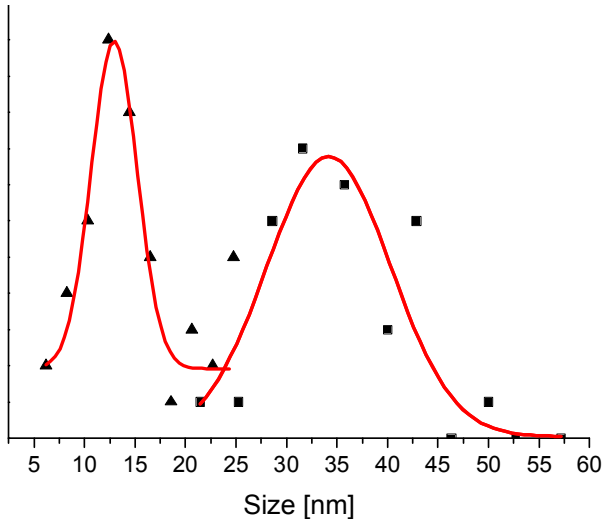

Figure 2: Size distributions of engine at EuroIV and engine at black smoke conditions

\subsection{Microstructure and morphology}

The typical morphology of F-soot is shown in the highresolution electron micrograph depicted in Fig. 3a. The chain-like secondary structure in Fig. 1a is resolved as agglomerates of a number of primary particles with sizes varying from 2 to $20 \mathrm{~nm}$. The agglomerates do not exhibit a defined profile or regular shape. The primary particles show multiple shell structures (fullerene-like). Multiple nuclei of particles arise from strongly bent ribbons. Large nuclei allow for a larger bending radius consisting of continuously bent basic structure units (BSU, [4]) and for the formation of flat sections of neighbouring structures. The primary particles then agglomerate to gain stability by a graphene-type dispersive interaction between bent strands of ribbons. The same morphology is observed in the fullerenic carbon in flame soot produced in a premixed laminar one-dimensional benzene/oxygen/argon combustion [5].

The high resolution TEM image of G-soot (Figure 3b) reveals a totally different morphology from that of the F-soot. G-soot exhibits a secondary structure consisting of a number of agglomerated spherical particles, a much more common morphology for soot. The electron micrographs in Fig. 3a and $3 \mathrm{~b}$ are depicted at the same magnification. The comparably large spherical particles in Fig. $3 \mathrm{~b}$ are made from homogeneously sized flat BSUs which are stacked such that the interplanar interaction is maximized while the outer surface is minimized. A similar gross morphology is observed in technical products of carbon black from understoichiometric low temperature flame pyrolysis of hydrocarbons. The smooth outer surface of the particles (left part of Fig. 3b) indicates a long reaction time to reach a minimum energy situation or a post synthetic oxidative episode that burned away the surface irregularities.

The large particle size of G-soot may suggest that there is a surface growth process in the engines run under black smoking conditions, in which the precursor molecules grow from some 1-2 $\mathrm{nm}$ to $10-30 \mathrm{~nm}$ before aggregation or chainforming coagulation take place. This is only possible if precursor molecules are readily available (rendering a rapid growth), or the 

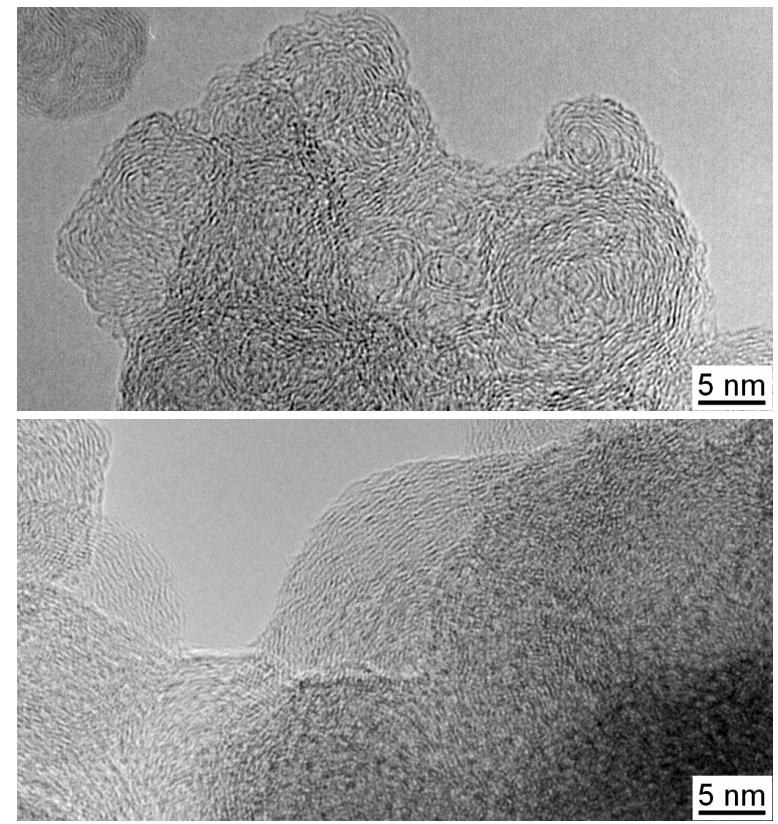

Figure 3: a) Fullerene-like soot of Euro-VI diesel engine; b) soot of the diesel engine operating at black smokine conditions.

surface of primary particles is less functionalised and therefore less prone to aggregation. The small particle size and the rough surface of F-soot suggest that in the EuroIV engine, due to the improved combustion of the diesel fuel, fewer precursor molecules are produced leading to slower growth of the primary particles. Additionally, the surface may be strongly functionalised so that the particles coagulate before they grow in size [6].

\subsection{Oxidation experiments}

Figure 4 shows the results of TG analysis in $5 \% \mathrm{O}_{2}$ for the soot samples. For both samples the produced gas analysis shows that the main product is $\mathrm{CO}_{2}$ with a minor amount of water. No other gas phase products were observed. The TG signal for both samples remains nearly the same until about $600 \mathrm{~K}$ where the F-soot begins to rapidly loose mass. The rate of mass loss for sample the F-soot reaches a maximum at $833 \mathrm{~K}$, but goes to zero at about $870 \mathrm{~K}$. The weight remains constant at $12.7 \%$ of the starting weight until at 925 $\mathrm{K}$ there is again a decrease of about $1 \%$ followed by a gradual mass loss until the end of the heating ramp at $1073 \mathrm{~K}$. The weight remaining at the end to the experiment is about $10 \%$ of the initial weight. TEM and energy dispersive XRay spectrometry studies reveal that the remnant containing mainly $\mathrm{Ca}, \mathrm{P}, \mathrm{S}$ is the ash of combusted engine lubricant oil. The gas phase analysis shows that $\mathrm{CO}_{2}$ evolution begins at $600 \mathrm{~K}$ and increasing to reach a maximum at $836 \mathrm{~K}$, corresponding to the first maximum in the rate of mass loss. There is an additional, smaller signal for water that also reaches a maximum at $836 \mathrm{~K}$. The loss of mass at $925 \mathrm{~K}$ is accompanied by a maximum in only the water signal. G-soot also begins to evolve $\mathrm{CO}_{2}$ at about $600 \mathrm{~K}$, but the concentration remains relatively low until about $680 \mathrm{~K}$. The rate of mass loss for G-soot then increases along with the signal for $\mathrm{CO}_{2}$ in the gas phase, and both reach a maximum at $936 \mathrm{~K}$. There is an additional, smaller signal for water in the gas phase that also reaches a maximum at $936 \mathrm{~K}$. The mass of the G-soot continues to decrease until $965 \mathrm{~K}$ when it reaches 0 . Figure 5 shows the mass loss with time for the F- and Gsoots while the samples were held at $653 \mathrm{~K}$ for 5 hours in $5 \% \mathrm{O}_{2}$. Both samples lose $3 \%$ of their mass during heating to $590 \mathrm{~K}$. Between $590 \mathrm{~K}$ and $653 \mathrm{~K}$ and for the first 2 hours thereafter the F-soot looses weight much more rapidly than the G-soot. This most easily oxidizable fraction of soot

a)

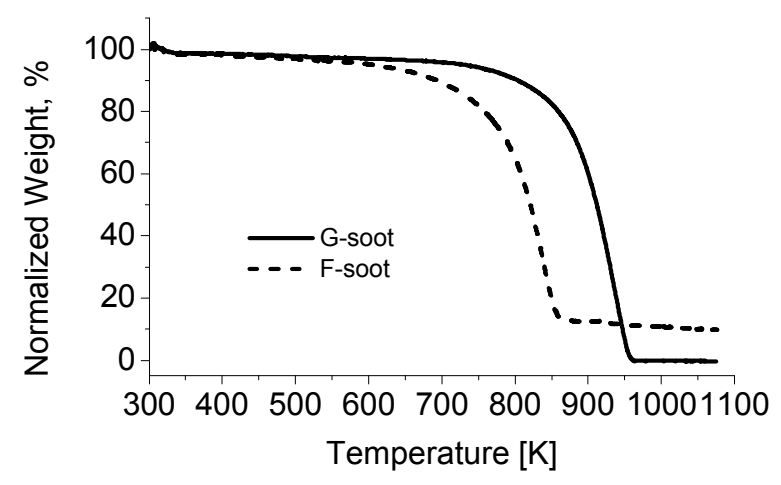

b)

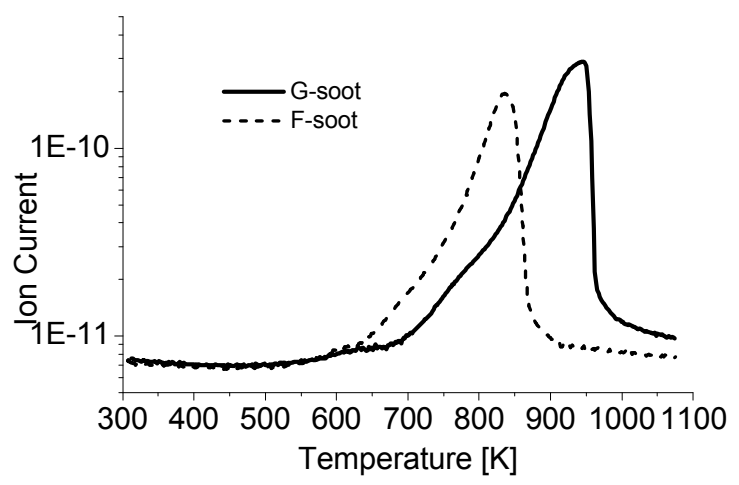

Figure. 4: a) TG analysis in $5 \%$ oxygen in nitrogen for Gsoot and F-soot; b) the evolution of $\mathrm{CO}_{2}(\mathrm{~m} / \mathrm{e}=44)$ during the TG analysis in $5 \%$ oxygen.

constitutes $8 \%$ of the F-soot. After about 4 hours at $653 \mathrm{~K}$ both samples continue to loose weight at a constant rate, the $\mathrm{F}$-soot at $2 \mathrm{wt} \% / \mathrm{h}$ and the G-soot at $0.4 \mathrm{wt} \% / \mathrm{h}$. The higher rate of oxidation of the F-soot could be due to the rough and defective surface that is more reactive than that of G-soot and to a higher surface area.

The TG analysis shows that the fullenere-like F-soot is much more reactive than G-soot. This morphology/microstructure-controlled reactivity of soot is in agreement with the earlier finding in temperature-programmed oxidation studies [7]. They show that as the presence of non 6-membered carbon rings with their olefinic electronic structure increases, and with the presence of chemically reactive 


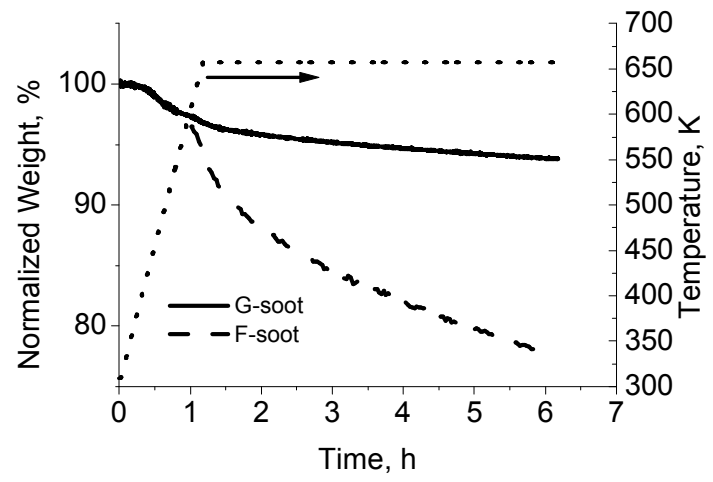

Figure. 5: Isothermal oxidation of soot samples at 653 $\mathrm{K}$ in $5 \%$ oxygen in helium $(100 \mathrm{ml} / \mathrm{min})$. Dotted line is temperature.

prism edges, nanocarbons with fullerenoid structure become more reactive than the more graphitized technical carbon blacks.

\section{Discussion}

The measures introduced for engine-internal emission reduction of commercial vehicles reduces the number of particles and therefore the mass of emitted soot particulate, but produce very fine and reactive fullerene-like soot. The fullerene-like soot may be the result of the optimised mixing behaviour of air and diesel fuel (air/fuel $>1.3$ ) in the combustion chamber. The optimised combustion process in EuroIV as compared to EuroI-III diesel engines prevents the formation of precursor molecules necessary for the growth of conventional spherical soot particles. However, the improved air/fuel ratio is still understoichimetric and a complete combustion of diesel fuel is not achieved. The changed boundary conditions in the combustion chamber (supersaturation, temperature, and pressure) thus lead to the formation of fullerene-like soot. It should be mentioned here that the formation of fullerene [6] and fullerene-like soot (fullerene black) [5] has previously only been reported in premixed, stationary benzene/oxygen flames at low pressure $(20-40$ Torr). The detailed mechanism for the formation of fullerene-like soot in the low emission diesel engines under non-stationary conditions at high pressure (160 000 Torr) still needs to be studied.

The F-soot of EuroIV diesel engine is very reactive. One reason is the small size-distribution of primary particles and therefore the expected high surface area. However, the cru- cial reason is seen in the multi-shell like fullerenoid structure of the F-soot with defective surface. The defective non 6-membered rings may produce highly localised olefinic electronic structures prone to the addition of molecular oxidants. One additional reason for the high reactivity of F-soot is its defective surface being functionalised with volatile groups.

The formation of much smaller and more reactive fullerenelike soot in the EuroIV diesel engine may have consequences for the future development of automotive pollution control. Certainly the reduction of particle sizes is undesirable due to potentially easier access of the fine particles to human lung membranes, although the toxicity of fullerenelike soot is still unknown. However it seems that, from the physico-chemical point of view the formation of fullerenelike soot in optimised diesel engines is an indicator of the great technological improvement in diesel engine combustion systems and suggests that we are now in the early stages of the development of particulate-free automotive engines. Further optimisation of the combustion process and the oxidation of soot within engines could be an alternative to the technology using soot particulate filter. Recently, a particulate matter (PM) catalyst system (PM-KAT ${ }^{\mathbb{R}}$ ) consisting of a platinum oxidation catalyst and metallic substrates with open cells for storage and oxidation of soot has been successfully developed for this purpose [8, 2]. The small particle size, highly defective surface structure, and more easily oxidised fullerene-like soot, identified in this work, are prerequisites for the catalytic automotive pollution control

\section{Conclusion}

Our investigations reveal that through the measures taken to decrease soot emission, the new, low-emission EuroIV diesel engine tested in the present work produces carbon particulate consisting of fullerenic primary particles. The optimised combustion conditions prevent the formation of larger, more stable spherical soot particle. The size of the new soot particulate is smaller, and the size-distribution narrower than that of soot produced in the EuroIII diesel engine run under black smoking conditions. The soot of the tested EuroIV diesel engine exhibits a highly defective microstructure and is much more easily oxidised, making its elimination through engine-internal oxidation possible.

\section{Aknowledgement}

This work is part of the project „Katalytisches System zur filterlosen kontinuierlichen Rußpartikelverminderung für Fahrzeugdieselmotoren" supported by the Bayerische Forschungsstiftung.

\section{References}

[1] a) CONCAWE, 1994, Motor Vehicle Emission Regulation and Fuel Specification-1994 update, Brussels, pp234 and b) http://www.dieselnet.com/standards (2003)

[2] E. Jacob, D. Rothe, R. Schlögl, D. S. Su, J.-O. Müller, R. Nießner, C. Adelhelm, A. Messerer, U. Pöschl, K. Müllen, C. Simpson, Z. Tomovic, Dieselruß: Mikrostruktur und Oxidationskinetik, H.P. Lenz (Hrsg.) 24. Internationales Wiener Motorensymposium, 15.-16. Mai 2003, Band 2: Fortschritt-Berichte VDI Reihe 12 Nr. 539 Düsseldorf: VDI-Verlag 2003, S. 19-45

[3] H.J. Stein, VDA Technische Kongress 2000, 265 
[4] A. Oberlin, High resolution TEM studies of carbonization and graphitization, in: P. Thrower (Edt.), Chemistry and Physics of Carbon 22, Dekker, New York (1989) 21-142

[5] W. J. Greco, J. B. Howard, L. C. Rainey, J.B. Vander Sande, Carbon 38 (2000) 597

[6] K.-H. Hohmann, Angew. Chem. Int. Ed. 37, 2434 (1998)

[7] T. Belz and R. Schlögl, Synthetic Metals 77, 223 (1996)

[8] E. Jacob, N. D’Alfonso, A. Döring, S. Reisch, D. Rothe, R. Brück, P. Treiber, PM-KAT: Nichtblockierende Lösung zur Minderung von Dieselruß für EuroIV-Nutzfahrzeugmotoren, H.P. Lenz (Hrsg.) 23. Internationales Wiener Motorensymposium, 25.-26. April 2002, Band 2: Fortschritt-Berichte VDI Reihe 12 Nr. 490 Düsseldorf: VDI-Verlag 2002, S. 196-216 